\title{
EFFECTIVE SIMPLE METHODS FOR NUMERICAL MODELLING OF MARINE ENGINES IN SHIP PROPULSION CONTROL SYSTEMS DESIGN
}

\author{
M. Altosole ${ }^{1}$ and M. Figari ${ }^{2}$ \\ ${ }^{1}$ Department of Naval Architecture, Marine Technology and Electrical Engineering, Genoa University, Genoa-16145, Italy, \\ Email: marco.altosole@unige.it \\ ${ }^{2}$ Department of Naval Architecture, Marine Technology and Electrical Engineering, Genoa University, Genoa-16145, Italy, \\ Email: massimo.figari@unige.it
}

\begin{abstract}
:
In the last year, the Department of Naval Architecture and Marine Engineering of Genoa University (now Department of Naval Architecture, Marine Technology and Electrical Engineering) collaborated to the design of the propulsion automation of two different naval vessels; within these projects the authors developed different ship propulsion simulators used to design and test the propulsion control schemes. In these time-domain simulators, each propulsion component is represented by a specific mathematical model, mainly based on algebraic and differential equations. One of the key aspects of the propulsion simulation is the engine dynamics. This problem in principle can be dealt with models based on thermodynamic principles, which are able to represent in detail the behaviour of many variables of interest (engine power and speed, air and gas pressures, temperatures, stresses, etc.). However, thermodynamic models are often characterized by a long computation-time and moreover their development usually requires the knowledge of specific engine information not always available. It is generally preferable to adopt simpler simulation models, for the development of which, very few kinds of information are necessary. In fact, for the rapid prototyping of control schemes, it is generally more important to model the whole plant (in a relatively coarse way) rather than the detailed model of some components. This paper deals with simple mathematical methods, able to represent the engine power or torque only, but they can be suitably applied to many types of marine engines in a straightforward way. The proposed simulation approaches derived from the authors' experience, gained during their activity in the marine simulation field, and they are particularly suitable for a fast prototyping of the marine propulsion control systems. The validation process of these particular models, regarding a Diesel engine, a marine gas turbine and an electric motor, is illustrated based on the sea trials data and engine manufacturers' data.
\end{abstract}

Keywords: Dynamic simulation, marine engines performance, gas turbine, propulsion control.

\section{NOMENCLATURE}
$a, b, c$
coefficients of the engine power
and torque equation
$Q_{P} \quad$ propulsor torque $[\mathrm{Nm}]$
$c_{I} \quad$ integral gain of the control equation of the shaftline
$c_{P}$ proportional gain of the control equation of the shaftline
$T_{H}$
thrust required by the hull [N]
propulsor thrust $[\mathrm{N}]$
$k_{\text {Power }}$ constant of the differential equation for the engine power
V
ship speed [m/s]
$k_{\text {Torque }}$
constant of the differential equation for the engine torque
Acronyms
reduction gear ratio
CODLAG
Combined Diesel eLectric And Gas
I
fuel flow rate $[\mathrm{kg} / \mathrm{s}]$
$C P P$
Controllable Pitch Propeller 
M. Altosole and M. Figari/ Journal of Naval Architecture and Marine Engineering 2(2011) 129-147

\begin{tabular}{|c|c|c|c|}
\hline$N$ & shaft speed [rps] & $D E$ & Diesel Engine \\
\hline$n_{c}$ & commanded shaft speed [rps] & $E P M$ & Electric Propulsion Motor \\
\hline$n_{E}$ & engine speed [rpm] & $G B$ & Gearbox \\
\hline$P$ & number of propulsors & GPS-RTK & $\begin{array}{l}\text { Global Positioning System-Real Time } \\
\text { Kinematics }\end{array}$ \\
\hline$t$. & time $[\mathrm{s}]$ & $G T$ & Gas Turbine \\
\hline$x, y, z$ & $\begin{array}{l}\text { exponents of the engine power } \\
\text { and torque equation }\end{array}$ & $M C R$ & Maximum Continuous Rating \\
\hline$J$ & $\begin{array}{l}\text { polar moment of inertia of the } \\
\text { whole shaftline reduced to shaft } \\
\text { speed }\left[\mathrm{kg} \mathrm{m}^{2}\right]\end{array}$ & $O D E$ & Ordinary Differential Equation \\
\hline$K_{I}$ & integral gain of the engine torque & $P I$ & Proportional Integral \\
\hline$K_{P}$ & $\begin{array}{l}\text { proportional gain of the engine } \\
\text { torque }\end{array}$ & PID & Proportional Integral Derivative \\
\hline$M$ & ship mass plus added mass [kg] & RT HIL & Real Time Hardware in the Loop \\
\hline$P_{B}$ & engine brake power [W] & $S G$ & Shaft Generator \\
\hline$\overline{P_{B}}$ & engine brake power setpoint [W] & $\begin{array}{l}T \\
C S\end{array}$ & Turbine Control System \\
\hline$Q_{B}$ & engine brake torque [Nm] & & \\
\hline
\end{tabular}

\section{Introduction}

Numerical simulation techniques in marine propulsion systems can be successfully used for many purposes, such as ship performance prediction in design and off-design conditions, machinery behaviour analysis and control systems development.

Since several years Genoa University, Naval Architecture-Marine Engineering-Electrical Engineering Department (DINAEL) and ABB Marine (now SEASTEMA), one of the most important players in ships' automation, are working in collaboration for the development of propulsion controllers for naval vessels. In particular, in the last years, ABB has introduced the 'ship numerical simulation' into the design methodology of the propulsion control systems of naval vessels.

The collaboration started in year 2003, to develop a dedicated software for the integration between the onboard automation and a GPS-RTK acquisition system for a corvette of 1500 tons displacement. By means of this software, during the normal in-service operations, it was possible to record some particular full scale measurements in order to validate the first complete propulsion and manoeuvring simulator developed at Genoa University, as described by Altosole et al. (2004).

After this positive trial, in year 2005 ABB and DINAEL started the development of the propulsion simulator of the new Italian Aircraft Carrier "Cavour"; the simulator was used to design and test the real propulsion controller. In particular, ABB designers used the ship simulator according to the Real Time Hardware in the Loop (RT HIL) simulation technique. In fact, Altosole et al. (2009) simulated the propulsion system by a numerical code linked in real time to the real hardware (the ABB propulsion controller), providing to the designer a realistic feedback before the installation on board of the real control system.

One of the great advantages of this design approach is obviously the reduction of the expensive and timeconsuming full-scale trials.

Nowadays, DINAEL and SEASTEMA are using the same simulation approach for the design of the propulsion controller of the FREMM Multipurpose Frigates, equipped with CODLAG propulsion. The first commissioning is expected in 2012, when the first vessel will be into service. 
In the simulation approach adopted by the authors, the several elements of the propulsion plant (such as the engine, the shaft line, the propeller, the hull and the automation) are numerically modelled as separated blocks, which are properly linked each other in order to represent the behaviour of the whole propulsion system.

One of the most complex tasks is certainly the modelling of the main engine, if a good level of fidelity is required. The final versions of the above mentioned propulsion simulators are based on thermodynamic engine models. In the thermodynamic approach, for instance followed by Benvenuto et al. (1998), each engine component (the cylinder, the governor, etc.) is modelled in a specific module, which combines performance maps with momentum, mass and energy equations.

Many studies exist in literature dealing with the performance prediction and the simulation of diesel engines; the choice of a suitable model depends mainly on the requirements of the considered application and on the available computational tools.

In the pioneering works, as described by Ledger and Walmsley (1971) and Hendricks (1989), the diesel engine performance evaluation is based on maps or empirical correlations, fitting dynamometer data; the only available output is engine torque or power as function of a few input parameters, such as rotational speed and fuel consumption. In these models, the dynamics of engine and relative subsystems (i.e turbocharger) is often taken into account by means of time constants. The study carried out by Woodward and Latorre (1984) represents a step forward as compared with those cited above, because it includes a more detailed simulation of the turbocharger and of the intake and exhaust manifolds. However, it is still considered very rough with respect to in-cylinder phenomena approaches.

More recently, complex mathematical models, including the thermodynamic in-cylinder phenomena and the turbocharger dynamics, are available by Kao and Moskwa (1995), Dimitrios T. Hountalas (2000) and Maftei et al. (2009). The most important advantage of these kinds of models is the reliable feedback regarding thermal and mechanical stresses of the simulated engine.

Gas Turbine (GT) simulation codes were developed since about 1950, as soon as computers were available. At the beginning, for the GT dynamics simulation, linear or iterative methods were used. Afterwards, thanks to computer developments, only the inter-component volumes method was used by Saravanamuttoo and Fawke (1971). The latter approach guarantees, in fact, a better correlation between simulation and physical phenomena. Some authors, as Benvenuto and Campora (2003 and 2005), developed GT dynamic simulation models, based on thermodynamics of the GT main components (compressor, combustor, turbines), for marine propulsion control applications.

However, it is not always possible to develop sophisticated thermodynamic models, mainly due to the lack of specific information required to set up a detailed model. Another possible disadvantage could be a not reliable simulation at very low loads of the engine, because the traditional mathematical theories, adopted for the engine thermodynamics description, are often developed mainly for design conditions.

Moreover, too complex mathematical models could be characterized by a long computational time, far from real time. In this case, these numerical models are useless if RT HIL simulation technique has to be used. Therefore, for some kinds of simulation approaches, it is more useful to represent the engine performance by means of more simplified models, not able to calculate detailed aspects but certainly characterized by a sufficient fidelity and short computational time. On this ground, it is proper to underline that in marine propulsion control applications, two different control layers are usually present: the engine governor (lower layer) and the propulsion controller (upper layer). The engine governor performs the fuel flow computation and drives the fuel actuator taking into account engine limits and overload protections; the propulsion controller allows the remote control of the propulsion system in the whole operational profile and checks the propulsion components behaviour against overloads. The 'upper' layer is normally designed to prevent the engine governor protections to operate.

If the simulation aim is to achieve useful information for the engine governor design, it is clear that a detailed numerical model of the engine is needed, because in this case only a simulator able to provide a detailed feedback, regarding thermal and mechanical stresses of the engine, can be a powerful tool for the governor designer. On the contrary, for the overall propulsion control system, it could be less important to deeply investigate the engine thermodynamics. In fact, it is generally sufficient to predict the global behaviour of the engine (torque and speed), on the ground of which the protection logics of the whole propulsion system can be assessed. With regard to this aspect, the control process for one shaft of the aircraft carrier Cavour is shown in Fig. 1 as an example. In the figure the following components are shown: the input and feedback signals of the 
ABB propulsion controller, the governors of the two engines (TCS: Turbine Control System), the two marine gas turbines (GTs) acting on the same shaft.

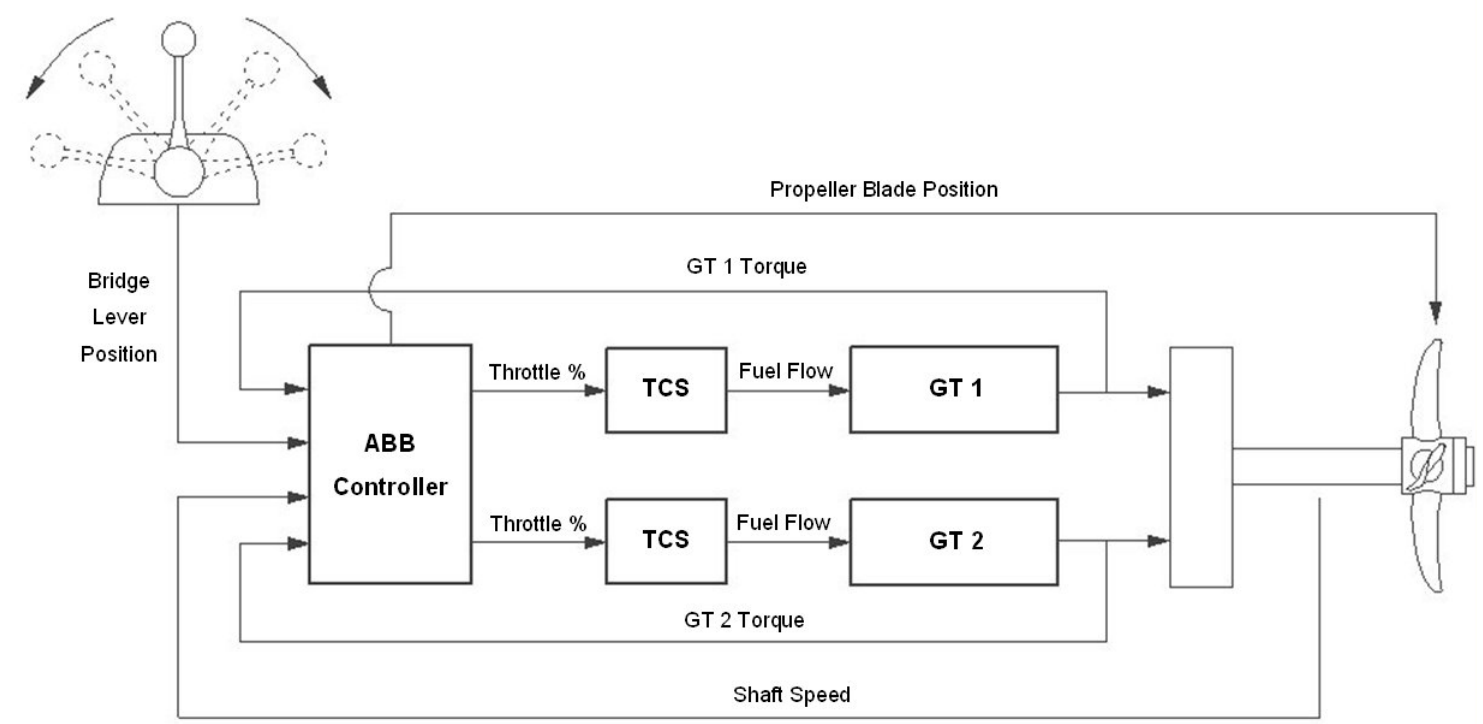

Fig.1: Propulsion control scheme

In the present paper a collection of simulation methods, representing the behaviour of several marine engines, to be used for the propulsion automation design, is presented. In particular, numerical models proposed by the authors are discussed hereinafter. The validation process of these particular models, regarding diesel engines, marine gas turbines and electric motors, is also illustrated on the ground of sea trials data or engine manufacturer data.

The application of the presented models is aimed to the calculation of the engine torque $Q_{B}$ to be used in the equations of ship dynamics, as follows:

$$
\left\{\begin{array}{l}
\dot{V}(t)=p T_{P}(V, n, t) \frac{1}{M}-T_{H}(V, t) \frac{1}{M} \\
\dot{n}(t)=Q_{B}(n, f, t) \frac{1}{2 \pi J}-Q_{P}(V, n, t) \frac{1}{2 \pi J} \\
\dot{m}_{F}(t)=-c_{P} \dot{n}(t)+c_{I}\left[n_{c}-n(t)\right]
\end{array}\right.
$$

where $n=n_{E}$ for two-stroke diesel engines and $n=n_{E} / i$ for gas turbines and four-stroke diesel engines. The first equation describes the longitudinal ship motion, the second is referred to the shaftline dynamics and the third equation represents the behaviour of the shaftline control system (PI governor). The complete definition of the system can be found in Altosole and Figari (2007a and 2007b).

\section{Engine Modelling by Mathematical Equations}

The first presented method of engine modelling is based on a system of two equations. The first equation, of the algebraic type, describes the engine state in terms of engine power and speed, according to its performance map. The second equation, differential, is used to represent the engine dynamics.

The general form of the equations comes from authors' assumptions that will be discussed in the following subsections. To set up the model for a particular engine, it is necessary to identify few parameters by fitting engine manufacturer data. 


\subsection{Low speed transients and steady state conditions}

The mathematical structure of the first equation, representing the engine steady state conditions, is based on the following considerations:

1) The brake power $P_{B}$ of a generic marine engine, in equilibrium with the power required by a generic propulsor (marine propeller or waterjet unit), may be roughly considered as a cubic law depending on the shaft speed:

$$
P_{B} \propto n_{E}^{3}
$$

and then the engine torque $Q_{B}$ :

$$
Q_{B} \propto n_{E}^{2}
$$

Relationships (2) and (3) can be analytically derived by considering the required power of a screw propeller acting behind a ship having a square resistance curve and with constant propulsive efficiencies. In all other cases (i.e. non-square resistance, variable propulsive efficiencies) it is an approximation of the required power.

2) The engine torque, in the most of its working area, may be considered proportional to the fuel flow $m_{F}$ :

$$
Q_{B} \propto m_{F}
$$

Relationship (4) is valid for a diesel engine at a fixed speed and in the hypothesis of constant engine efficiency, however it can be considered a good starting point for the scope of the present work also for gas turbines.

Expression (3) can be written:

$$
\frac{Q_{B d}}{n_{E d}{ }^{2}}=\frac{Q_{B}}{n_{E}{ }^{2}}
$$

where subscript $d$ means design condition.

And then:

$n_{E d}=n_{E}\left(\frac{Q_{B d}}{Q_{B}}\right)^{\frac{1}{2}}$

Substituting Relation (4) into Equation (6):

$$
n_{E d}=n_{E}\left(\frac{m_{F d}}{m_{F}}\right)^{\frac{1}{2}}
$$

Then, from Equations (2) and (7):

$$
P_{B d}=P_{B}\left(\frac{m_{F d}}{m_{F}}\right)^{\frac{3}{2}}
$$

Two typical load diagrams, for a four-stroke marine Diesel engine and a marine gas turbine, are respectively reported in Fig. 2 and Fig. 3.

The two figures show engine power curves, depending on engine speed, at constant fuel flow (percentage of the maximum fuel flow rate). These kinds of information can be usually achieved or derived from the traditional performance maps provided by engines manufacturers. 


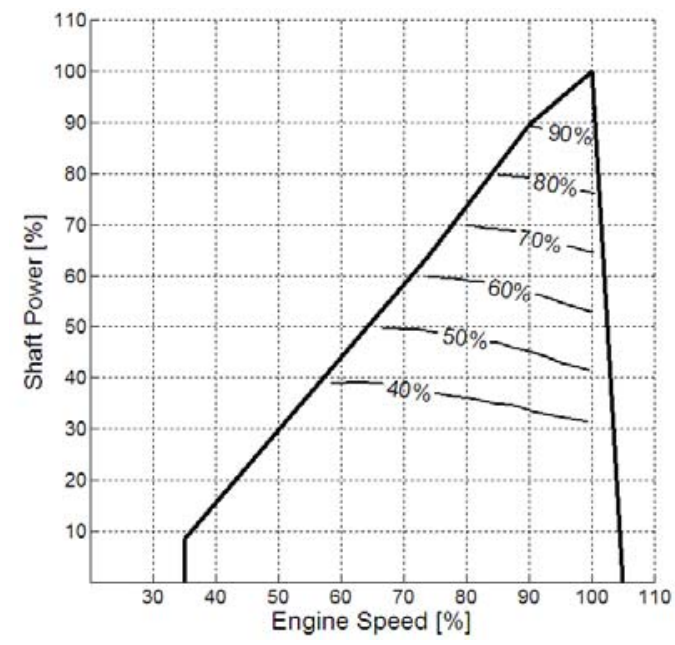

Fig. 2: Diesel engine, typical performance map at constant fuel flow rate

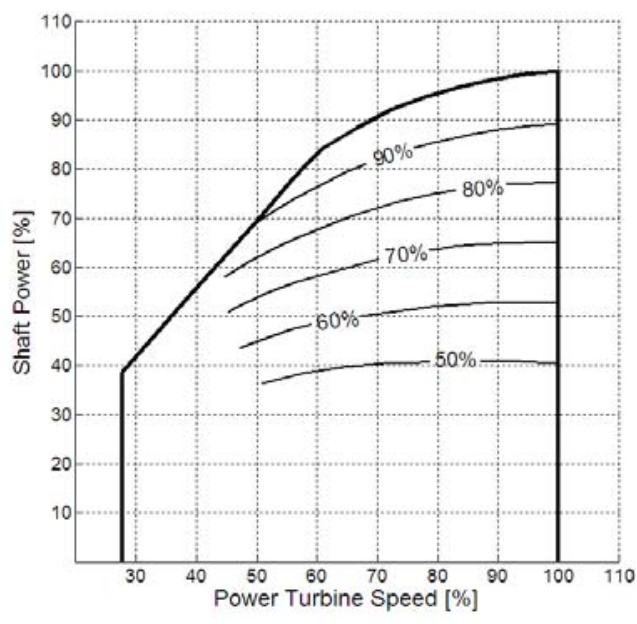

Fig. 3: Marine gas turbine, typical performance map at constant fuel flow rate

3) The engine power, for a constant fuel flow rate, can be represented by a third-order polynomial as a function of engine speed. For instance, for the fuel flow rate corresponding to the design condition:

$P_{B d}=a n_{E d}{ }^{3}+b n_{E d}{ }^{2}+c n_{E d}$

where the coefficients $a, b, c$ are calculated by fitting three arbitrary points of the power-speed curve corresponding to the design fuel flow rate.

Using hypothesis 1), 2) and 3) by substituting Equations (7) and (8) into Equation (9) gives:

$P_{B}=\left(\frac{m_{F}}{m_{F d}}\right)^{\frac{3}{2}}\left[a\left(\frac{m_{F d}}{m_{F}}\right)^{\frac{3}{2}} n_{E}{ }^{3}+b\left(\frac{m_{F d}}{m_{F}}\right) n_{E}{ }^{2}+c\left(\frac{m_{F d}}{m_{F}}\right)^{\frac{1}{2}} n_{E}\right]$

In order to have a more suitable correspondence between Equation (10) and the power-speed characteristics of a generic marine engine, Equation (10) can be written in the following general form:

$P_{B}=\left(\frac{m_{F}}{m_{F d}}\right)^{x}\left[a\left(\frac{m_{F d}}{m_{F}}\right)^{x} n_{E}{ }^{3}+b\left(\frac{m_{F d}}{m_{F}}\right)^{y} n_{E}{ }^{2}+c\left(\frac{m_{F d}}{m_{F}}\right)^{z} n_{E}\right]$

Where the exponents $x, y, z$ have to be set according to the particular marine engine to be represented.

The relation between $x, y$ and $z$ can be assessed by the structure of Equation (10), therefore:

$x=\frac{3}{2} y \quad z=\frac{1}{2} y$

For a real case of a marine gas turbine LM 2500 (by Avio) type for military applications, a proper modelling of the power is obtained with the following numerical values:
$x=1.35$
$y=0.9$
$z=0.45$
$a=1.77 \mathrm{e}-7$
$b=-0.0025$
$c=11.497$
$m_{f d}=1.2[\mathrm{~kg} / \mathrm{s}]$
$0<m_{f}<1.2[\mathrm{~kg} / \mathrm{s}]$ 
Where $m_{f d}$ is the fuel consumption corresponding to the maximum continuous rating (MCR) of the gas turbine.

It means that Equation (4) has to be revised accordingly:

$Q_{B} \propto m_{F}^{0.9}$

For the case of a typical four-stroke marine diesel engine, for instance, Wärtsilä W26X engine, the following values can be applied:
$x=1.05$
$y=0.7$
$Z=0.35$
$a=2.3156 \mathrm{e}-7$
$b=-8.5014 \mathrm{e}-4$
$c=0.8936$
$m_{f d}=0.27[\mathrm{~kg} / \mathrm{s}]$
$0<m_{f}<0.337[\mathrm{~kg} / \mathrm{s}]$

Where $m_{f d}$ is the engine fuel consumption corresponding to $80 \%$ MCR.

Also in this case Equation (4) has to be revised accordingly:

$Q_{B} \propto m_{F}^{0.7}$

The good agreement between the manufacturer data and this particular numerical modelling, referred to the marine gas turbine LM 2500 (by Avio) and W26X Diesel engine (by Wärtsilä), are respectively shown in Fig.4 and Fig.5, where the power curves at constant fuel consumption (solid lines) are compared with the results (dash dot lines) given by Equation (11). All the numerical values of the mentioned coefficients have been evaluated in accordance with the following units: $\mathrm{kW}$ for power and rpm for engine speed.

\subsection{Models for transient behaviour}

As regards the engine dynamics the following equation, referred to the power, is proposed:

$$
\frac{d P_{B}}{d t}(t)=-k_{\text {power }} P_{B}(t)+k_{\text {power }} \bar{P}_{B}
$$

where $\overline{P_{B}}$ represents the steady state value of the power at the equilibrium condition; it is calculated by Equation (11), while the coefficient $k_{\text {power }}$ should be assessed on the ground of experimental data.

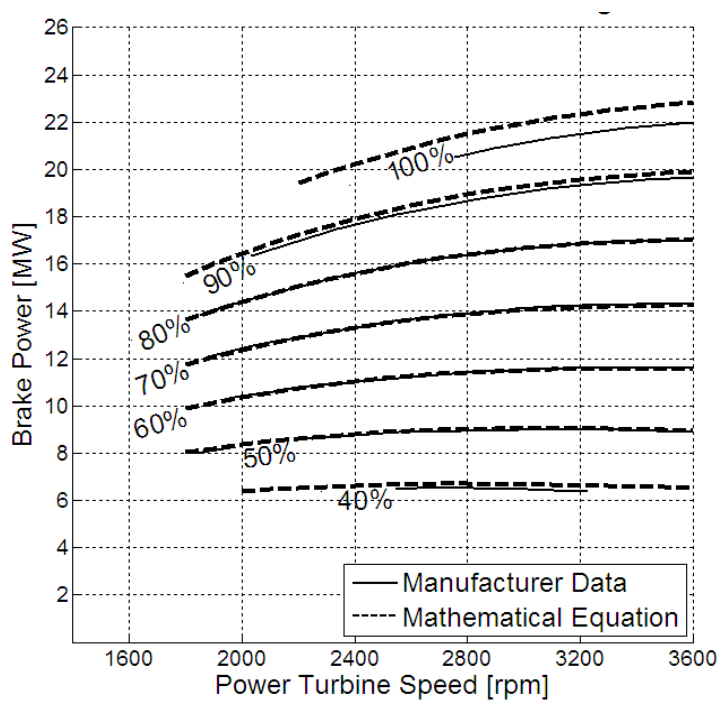

Fig. 4: Comparison between manufacturer data and computed results for LM2500 Gas Turbine

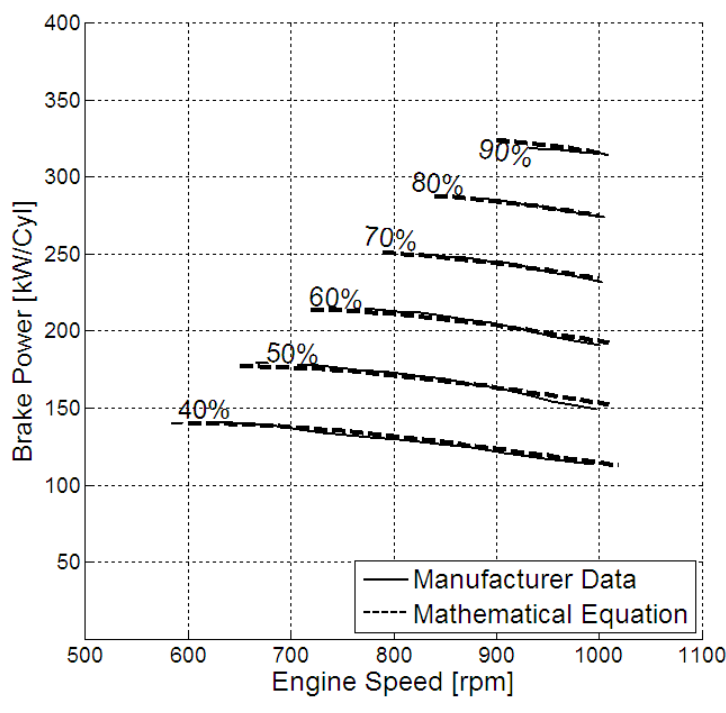

Fig. 5: Comparison between manufacturer data and computed results for W26XN Diesel Engine 
Equation (15) has been selected on the base on full scale records and simulation results; the equation represents the 'normal' behaviour of a controlled engine that is driven by its control system to the power setpoint $\overline{P_{B}}$. Therefore the final mathematical system proposed by the authors to represent the engine power behaviour is:

$$
\left\{\begin{array}{l}
\overline{P_{B}}=\left(\frac{m_{F}}{m_{F d}}\right)^{x}\left[a\left(\frac{m_{F d}}{m_{F}}\right)^{x} n_{E}{ }^{3}+b\left(\frac{m_{F d}}{m_{F}}\right)^{y} n_{E}{ }^{2}+c\left(\frac{m_{F d}}{m_{F}}\right)^{z} n_{E}\right] \\
\frac{d P_{B}}{d t}(t)=-k_{\text {Power }} P_{B}(t)+k_{\text {Power }} \overline{P_{B}}
\end{array}\right.
$$

or, developing the System (16), the following unique differential equation is obtained:

$$
\frac{d P_{B}}{d t}(t)=-k_{\text {Power }} P_{B}(t)+k_{\text {Power }}\left(\frac{m_{F}}{m_{F d}}\right)^{x}\left[a\left(\frac{m_{F d}}{m_{F}}\right)^{x} n_{E}{ }^{3}+b\left(\frac{m_{F d}}{m_{F}}\right)^{y} n_{E}{ }^{2}+c\left(\frac{m_{F d}}{m_{F}}\right)^{z} n_{E}\right]
$$

Since the scope of the modelling is the synthesis of the propulsion controller (dynamic system), the engine dynamics, Equation (17), has to be evaluated in conjunction with the ship dynamics given by Equations (1) because of the mutual interaction. System (18) contains the equations of the ship dynamics, her propulsion and control.

$$
\left\{\begin{array}{l}
\dot{V}(t)=p T_{P}(V, n, t) \frac{1}{M}-T_{H}(V, t) \frac{1}{M} \\
\dot{n}(t)=\frac{P_{B}\left(n, m_{F}, t\right)}{2 \pi n(t)} \frac{1}{2 \pi J}-Q_{P}(V, n, t) \frac{1}{2 \pi J} \\
\dot{m}_{F}(t)=-c_{P} \dot{n}(t)+c_{I}\left[n_{c}-n(t)\right] \\
\dot{P}_{B}(t)=-k_{\text {Power }} P_{B}(t)+k_{\text {Power }}\left(\frac{m_{F}}{m_{F d}}\right)^{x}\left[a\left(\frac{m_{F d}}{m_{F}}\right)^{x} n_{E}{ }^{3}+b\left(\frac{m_{F d}}{m_{F}}\right)^{y} n_{E}{ }^{2}+c\left(\frac{m_{F d}}{m_{F}}\right)^{z} n_{E}\right]
\end{array}\right.
$$

\subsection{Numerical modeling validation}

In previous paragraphs, a first kind of validation for the proposed method is shown on the ground of manufacturers engine data regarding steady state conditions $\left(\dot{P}_{B}(t)=0\right)$. As far as transient condition is concerned, due to the lack of information from engines manufacturers, the engine dynamic represented by Equation (17) is validated on the ground of results achieved by simulation. Engine thermodynamic models, developed at Genoa University, are used for the validation. In particular, the thermodynamic models of the diesel engine Wärtsilä W26XN, installed on board of the Italian corvette “Comandante Bettica”, and of the gas turbine LM2500, installed on board of the Italian aircraft carrier "Cavour", are herein considered. The used models were previously validated on the basis of data recorded during sea trials, as reported in Altosole et al. (2004) and Altosole et al. (2009), respectively for the corvette "Comandante Bettica” and for the aircraft carrier "Cavour". The ships main characteristics are illustrated in Table 1 and Table 2.

Table 1: Main characteristics of the aircraft carrier "Cavour”

\begin{tabular}{|c|c|}
\hline Overall Length & $244 \mathrm{~m}$ \\
\hline Maximum Beam & $39 \mathrm{~m}$ \\
\hline Displacement & $27100 \mathrm{t}$ \\
\hline Maximum Ship Speed & 30 knots \\
\hline Main Engines & LM2500, 4 x 22000 kW \\
\hline Propellers & 2x5-bladed CP propellers \\
\hline
\end{tabular}


Table 2: Main characteristics of the corvette "Comandante Bettica"

\begin{tabular}{|c|c|}
\hline Overall Length & $88.6 \mathrm{~m}$ \\
\hline Maximum Beam & $10.2 \mathrm{~m}$ \\
\hline Displacement & $1512 \mathrm{t}$ \\
\hline Maximum Ship Speed & 25 knots \\
\hline Main Engines & Wärtsilä W26XN, 2 x 6480 kW \\
\hline Propellers & 2x4-bladed CP propellers \\
\hline
\end{tabular}

Unfortunately, the direct comparison between the results of the proposed equations and the sea trials data is not possible in the case of the diesel engine, because the torque meter instrument was not installed on board of the "Comandante Bettica" at the time of the considered sea trials, therefore the diesel engine torque was not available. The diesel engine thermodynamic model was validated on the basis of other important data, mainly regarding the turbocharging system (air pressure and temperature, exhaust gas temperature and turbocharger speed).
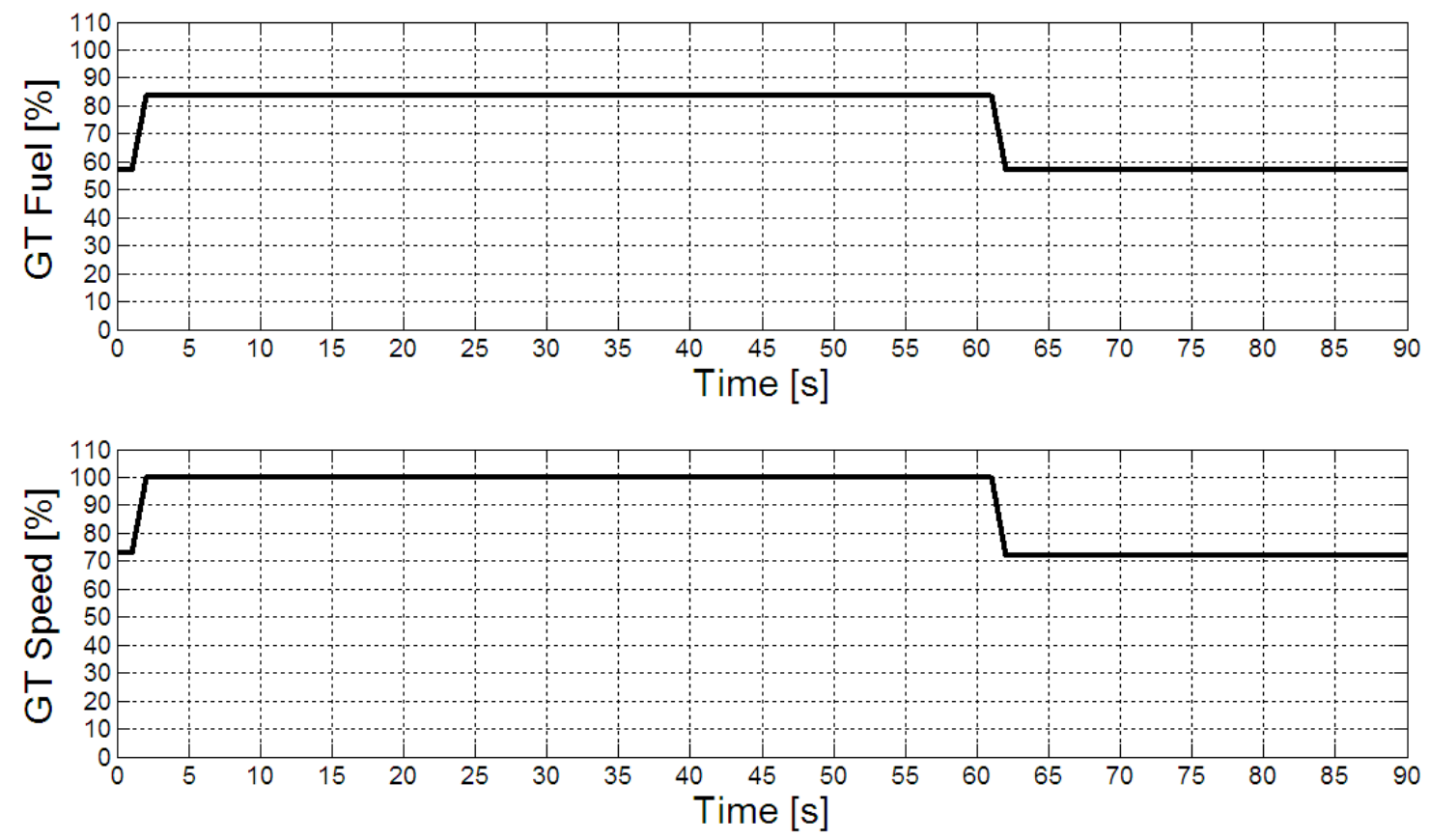

Fig.6: Simulation input for the LM2500 gas turbine

On the contrary, in the case of the sea trials regarding the aircraft carrier "Cavour", the records about the gas turbine power and torque are available. However, in order to carry out an homogeneous kind of analysis, it has been decided to report the same data comparison for both types of marine engines.

The results of two typical marine engines manoeuvres are compared, the calculations are carried out by Equation (17), and by the corresponding thermodynamic models. Time histories of the GT speed and fuel flow rate, i.e. the engine simulation input, are reported in Fig. 6. The engine power, simulated by Equation (17), is compared in Fig. 7 with the power simulated by the gas turbine LM 2500 thermodynamic model.

The good agreement, shown in the figure for the transient condition (engine acceleration and deceleration), is achieved by means of a numerical value for constant $k_{\text {Power }}$ equal to 0.5 .

A similar manoeuvre for the Diesel Engine (DE) W26XN is shown in Fig. 8 and Fig. 9. In this case, the adopted constant $k_{\text {Power }}$ is equal to 1.5 .

All the numerical solutions of Equation (17), shown in the previous figures, are solved by the Dormand-Prince method, a member of the Runge-Kutta family of ODE (Ordinary Differential Equations) solvers. 
M. Altosole and M. Figari/ Journal of Naval Architecture and Marine Engineering 2(2011) 129-147

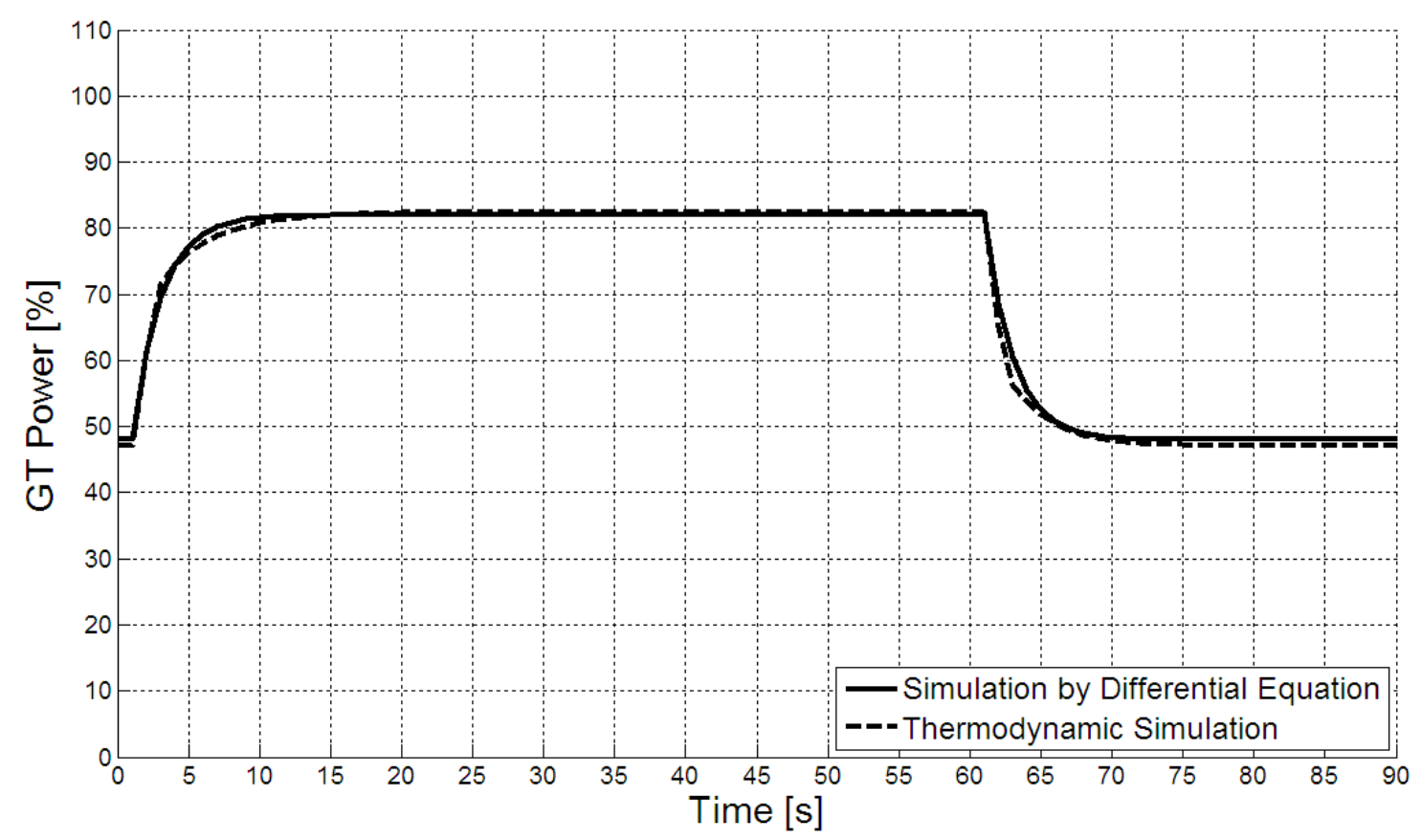

Fig.7: Comparison between the GT power simulated by differential equation and GT power simulated by the thermodynamic model
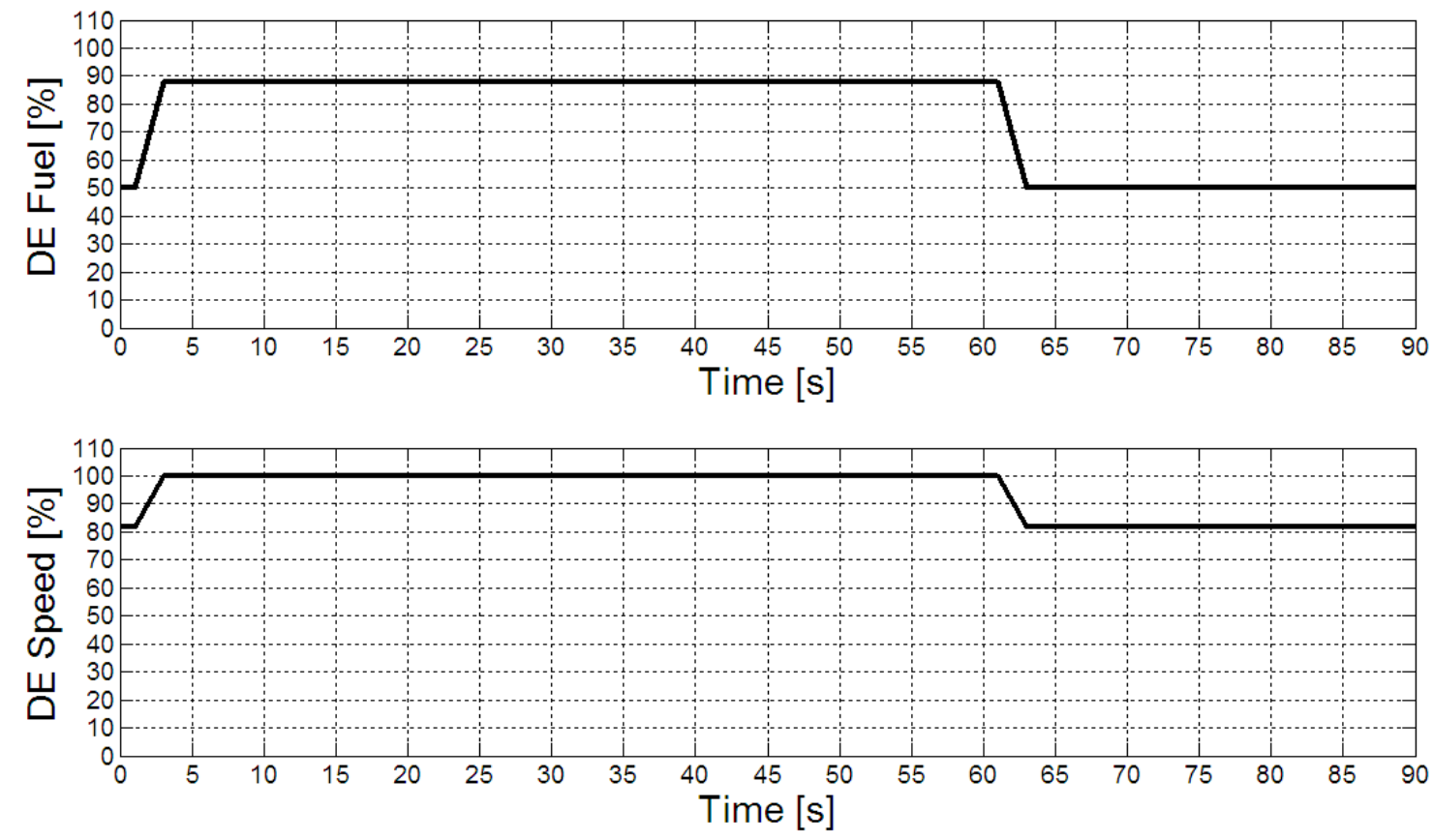

Fig.8: Simulation input for the W26XN Diesel Engine 


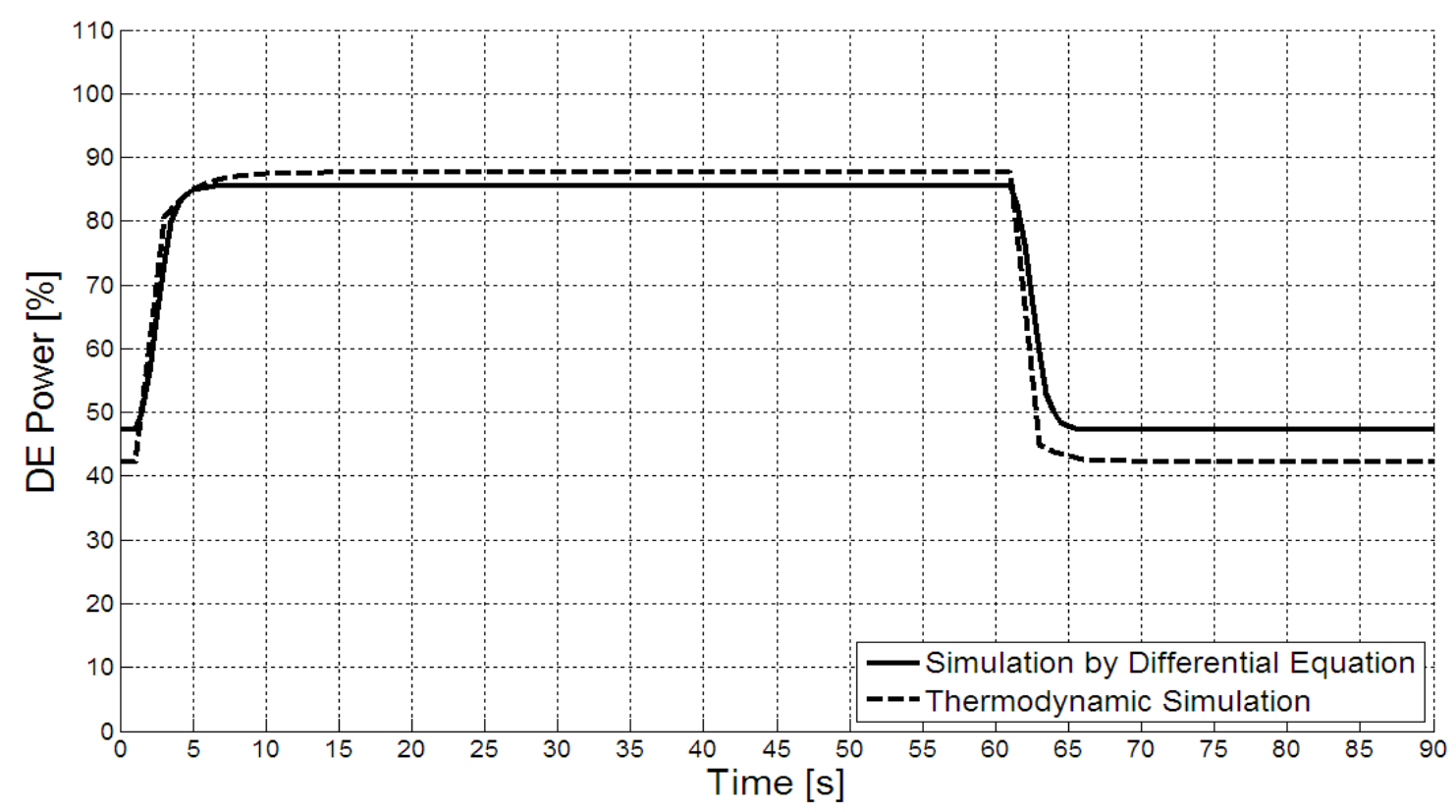

Fig.9: Comparison between the Diesel Engine power simulated by differential equation and the Diesel Engine power simulated by the thermodynamic model

\section{Engine Modelling by Numerical Surfaces}

The precise knowledge of mathematical equations is very useful in order to make easier and straightforward the development of numerical codes regarding complex physical systems. Moreover, in the case of dynamic systems simulation, the knowledge of the analytical structure of the differential equation is extremely important to carry out reliable stability analysis for the control of the system to be studied, as shown in Altosole and Figari (2007b). Unfortunately, the introduced mathematical equations for the numerical modelling of marine gas turbines and diesel engines are not usually very reliable at very low engine loads. However, the same problem is often present also by using thermodynamic numerical models. In order to overcome this difficulty, one of the most effective methods is the use of maps, based on engine manufacturer data (a post calibration on the base on experimental data recorded on board during the full operability of the ship is helpful for the future use of the models; with regard to this, further information can be found in Appendix).

The engine power can be simulated by a numerical surface depending on engine speed and fuel consumption flow rate. In particular, in Fig. 10, the power surface of the LM2500 gas turbine is reported. The surface has been modelled on the ground of the load diagram provided by the engine manufacturer and then properly corrected by use of the sea trials data of the aircraft carrier "Cavour". In fact, sea trials data have been used to extend the power surface also at very low engine loads, where test bed data were not available. In such a way only the steady state conditions of the engine can be represented; then to represent the dynamics of the engine Equation (17) can be used.

The simulation approach is the same of the previous paragraph but the use of the surface allows to simulate the entire working area of the engine. This kind of simulation approach, referred to the LM2500 gas turbine, is illustrated in Fig. 11, where the numerical surfaces, representing the gas generator speed and the inlet power turbine temperature, are also used. Therefore this engine model is able to predict also the gas generator speed and the gas turbine temperature, two important variables to be monitored in the case of a proper control of the engine. 


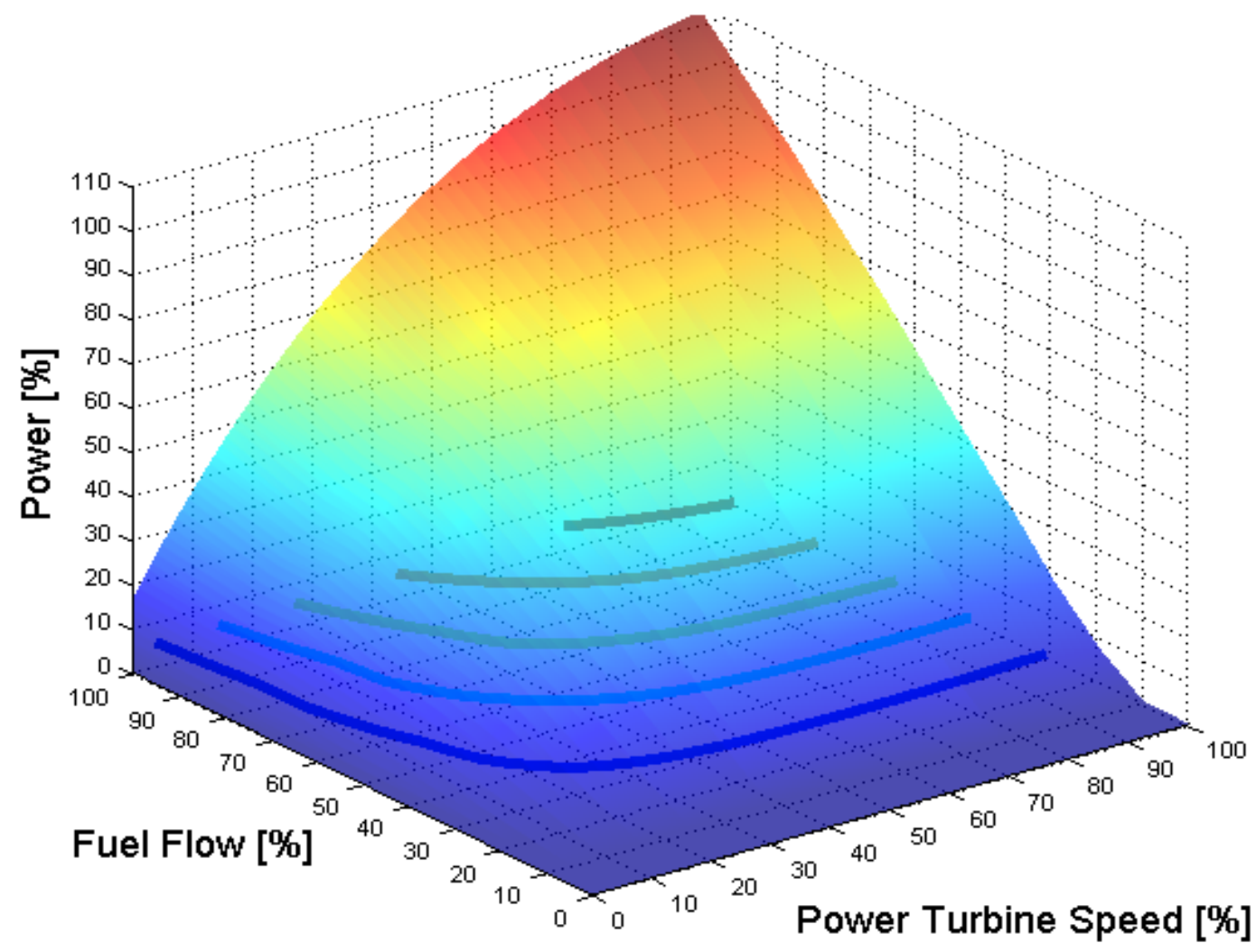

Fig.10: Power surface of the Gas Turbine LM2500

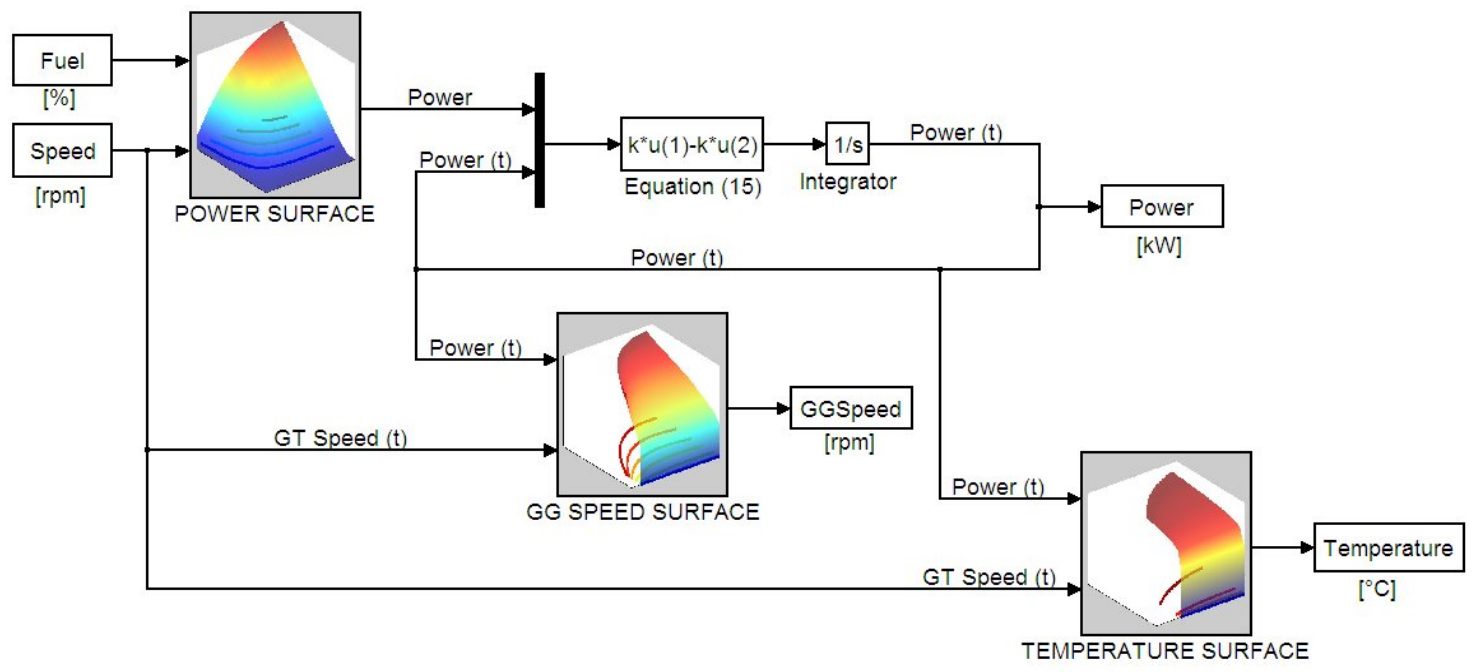

Fig.11: Simulation approach by using numerical surfaces

The same manoeuvre, illustrated in the previous Fig. 6 and Fig. 7, is performed again by the GT surface model; the comparison with the GT power, achieved by the corresponding thermodynamic model, is reported in Fig. 12. 


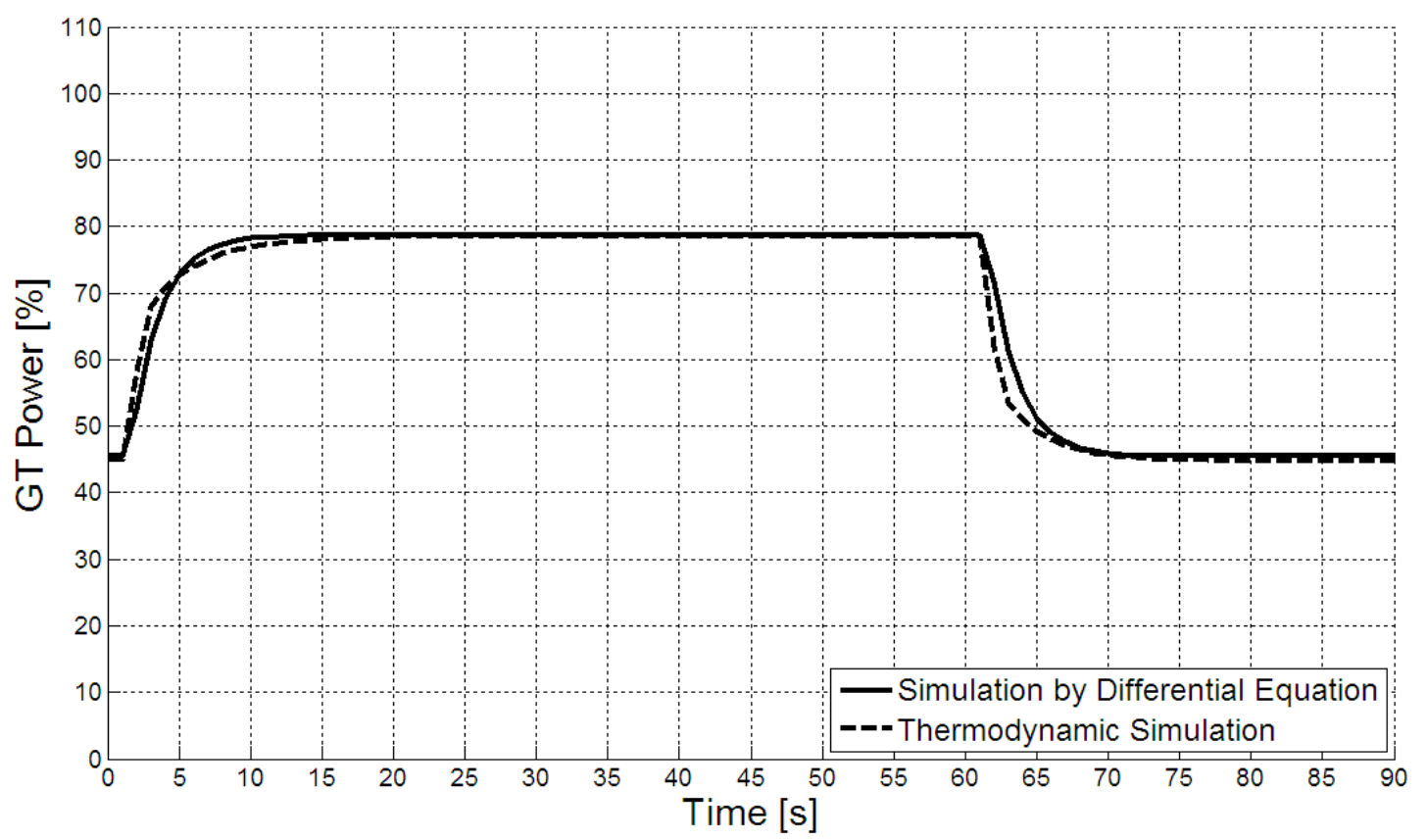

Fig.12: Comparison between GT power simulated by numerical surfaces and GT power simulated by the thermodynamic model

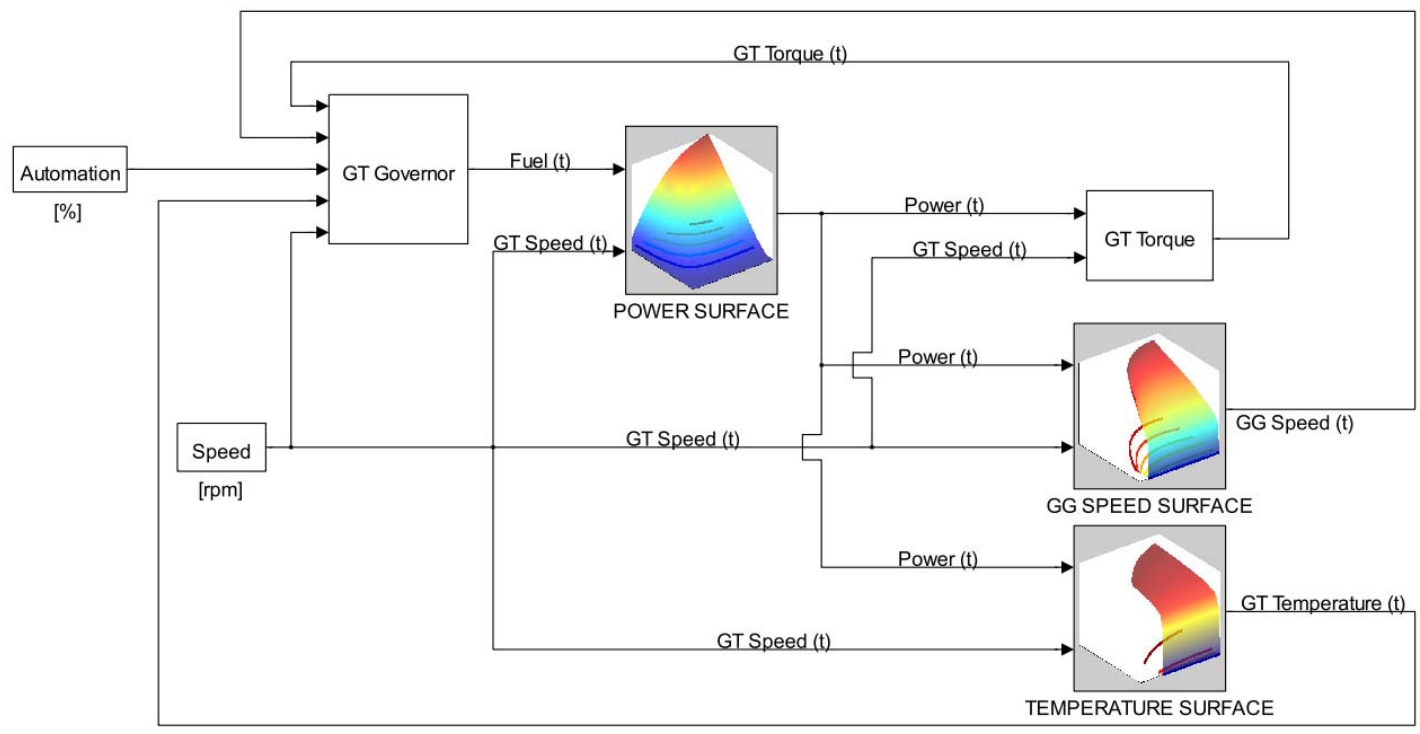

Fig.13: Simulation approach by using numerical surfaces and the governor dynamics

\subsection{The influence of the governor performance}

Generally the dynamics of the marine engines mainly depend on the governor performance. Then, in the above proposed methods, the numerical value of the factor $k_{\text {power }}$ includes also the governor dynamics.

With respect to this aspect, a more reliable assessment of the engine dynamics could be made on the base on the knowledge of the governor action. 
In the previous simulation approach (Fig. 11), the GT power transient is achieved by Equation (17), on the basis of the steady state working points calculated by means of the interpolation on the power surface, depending on GT speed and fuel. In this case, the numerical value of the fuel flow is constant because the GT governor is not modelled.

Instead, if the governor system is known, the previous GT simulation approach shown in Fig. 11, is modified as illustrated in Fig. 13, where the GT governor is explicitly modelled.

The subsystem representing the GT governor model is illustrated in Fig. 14, where it is possible to see the calculation of the GT fuel flow consumption by means of a PID algorithm acting on the Gas Generator speed error. A linear relationship between the GT throttle demand (i.e. the signal calculated by the ship propulsion automation) and the Gas Generator speed, is adopted. By the PID action, the signal to the fuel valve is obtained and then the GT fuel flow. In Fig. 14 several protections (over torque, over speed, acceleration and over temperature) are also included.

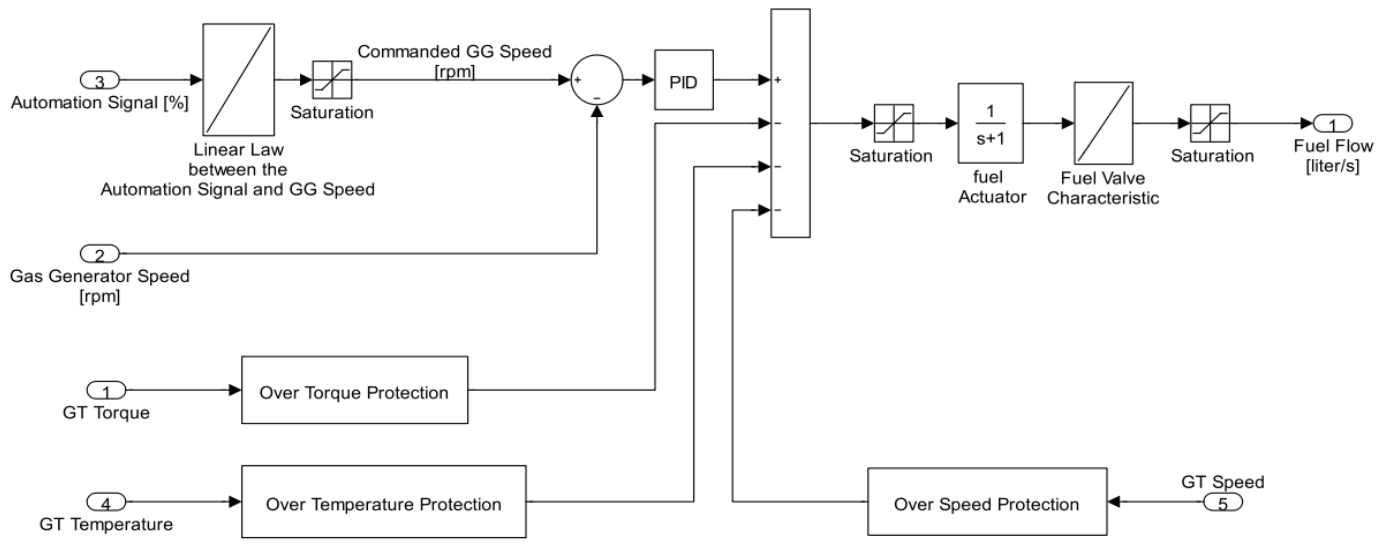

Fig.14: GT governor simulation process

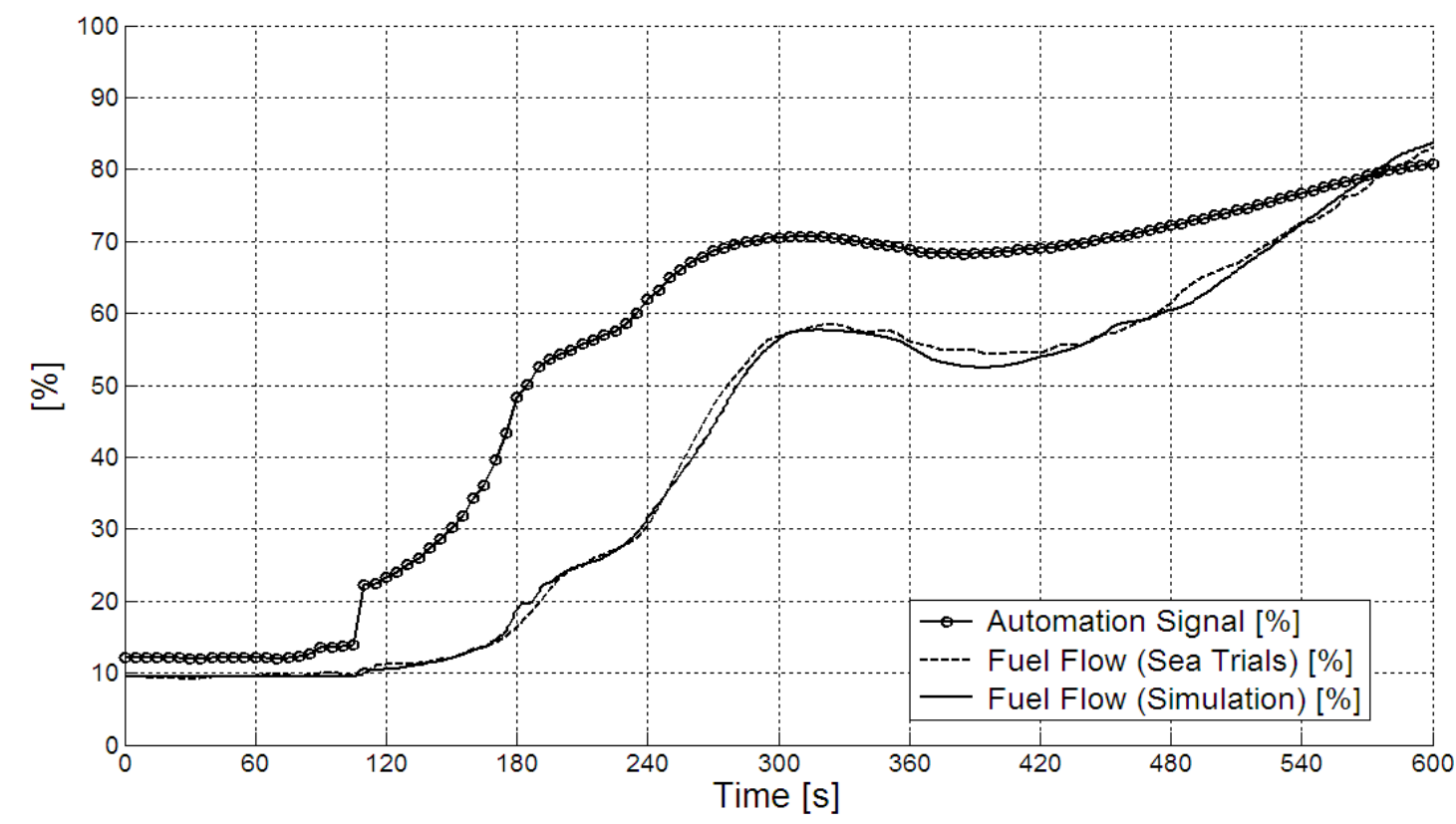

Fig.15: GT governor performance

The level of accuracy of the last proposed simulation approach can be assessed by Fig. 15 and Fig. 16. In particular, the influence of the governor dynamics on the GT dynamics is shown in Fig. 15, where the comparison between simulated results and sea trials records of GT fuel flow rate is shown. The actual fuel flow 
rate is the consequence of the automation signal, which is converted into fuel flow in accordance to the TCS control logics illustrated in Fig. 14. From this point of view, the comparison illustrated in Fig. 15 is helpful to assess the level of accuracy of the TCS numerical modelling. The automation signal reported in Fig. 15 is taken from the sea trials records performed on board of the aircraft carrier "Cavour"; the simulation uses the automation signal as input in order to have a consistent comparison of the fuel flow rate.

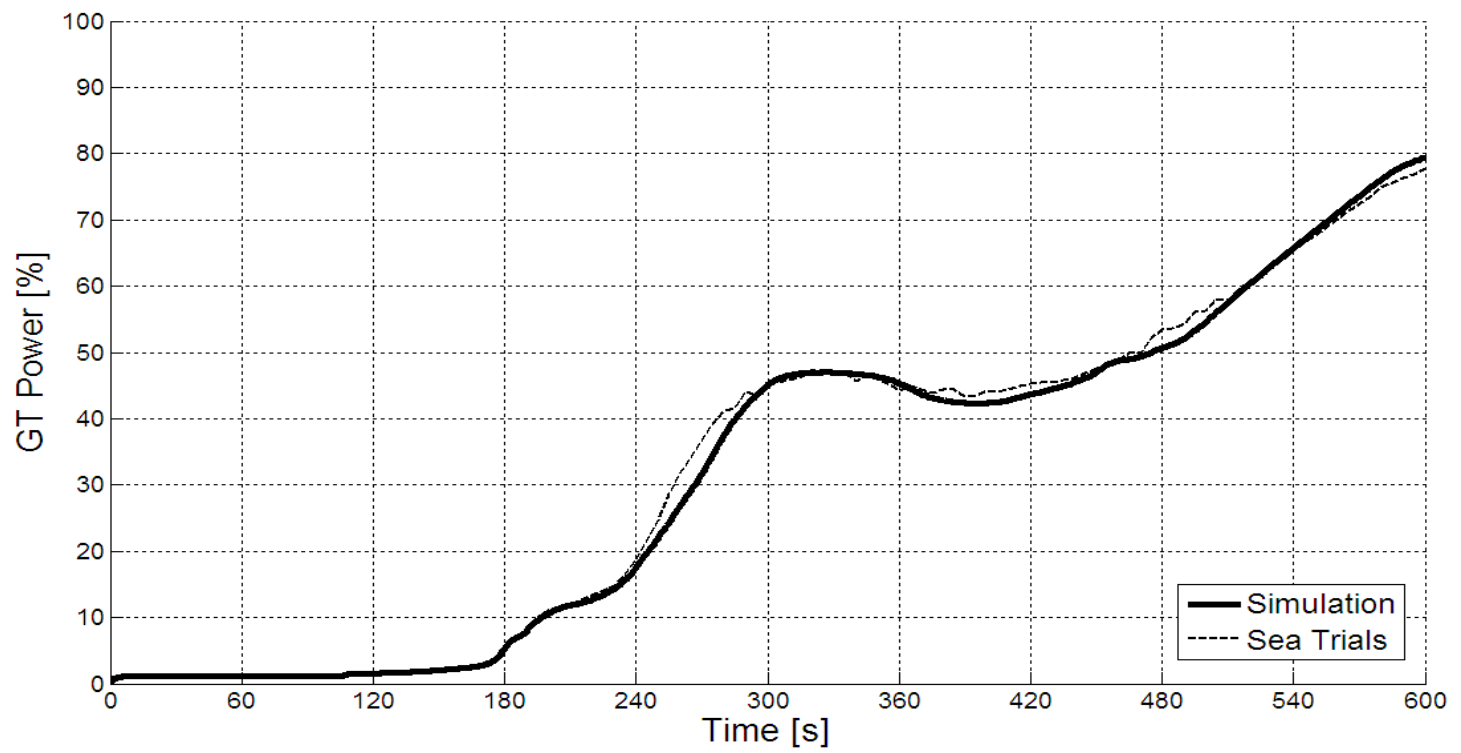

Fig.16: Comparison between simulation and sea trials data

In Fig. 16 the comparison between GT power, respectively by simulation and at sea trials records, for the same input shown in Fig.15, is reported.

\section{Engine Modelling by a PI action}

Another very general and simple way to represent a marine engine is illustrated in Fig. 17, where the computation of the engine torque is highlighted. By this approach the torque is simply calculated according to a proportional and integral action (PI) on the speed error. In the simulation process, the engine actual speed is compared with the engine speed commanded by the governor and then the engine torque is adjusted by the PI action in order to achieve and maintain the desired engine speed. In the simulation code reported in Fig. 17, the engine governor together with its specific input are present too.

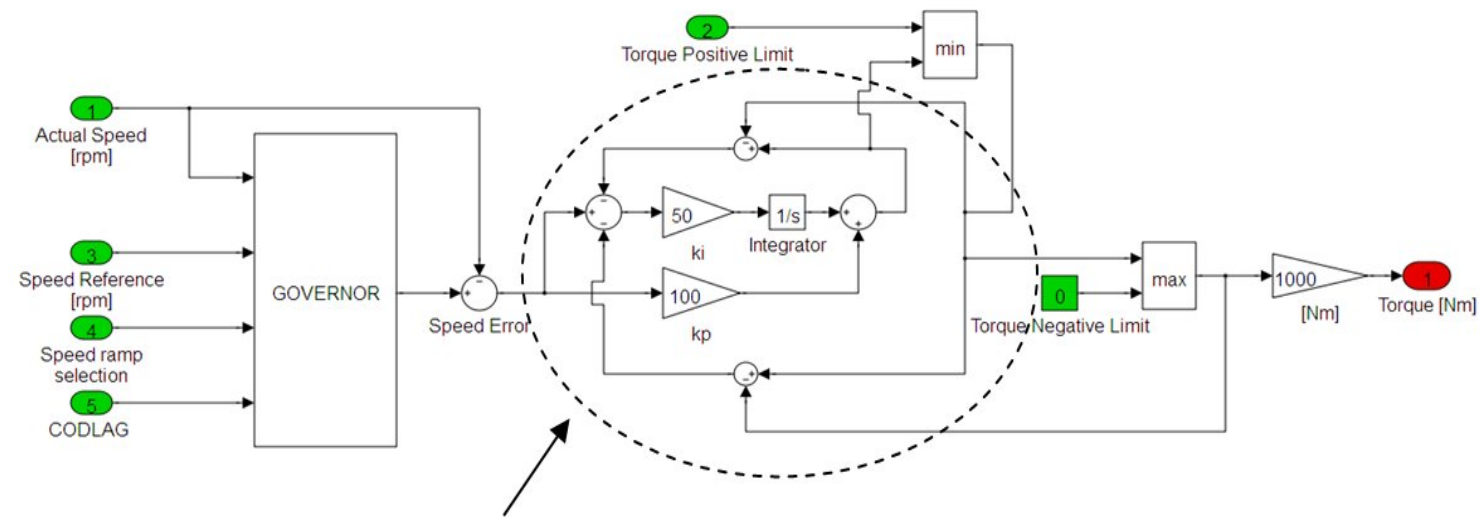

PI action

Fig.17: Simulation approach for the torque of an electric motor 
By this technique only the output of the engine is represented, without any reference to the physical or technical characteristics of the machine. This approach is suitable only for a broad, or high level, simulation. In particular, the figure is referred to the simulation code, developed in Matlab-Simulink, of the electric motor used on board of the FREMM Class Frigates.

The PI action, adopted for a simple computation of the engine torque, can be corrected by the presence of some proper protections (named Torque Positive and Negative Limits in the Simulink code shown in the figure). In order to provide a more intelligible reading of the adopted method, the simulation process only for the torque computation is described in Fig. 18.

The simulation process illustrated in Fig. 18, can be generally represented by the following equation:

$Q_{E}(t)=K_{P} \cdot\left[n_{c}-n(t)\right]+K_{I} \cdot \int\left[n_{c}-n(t)\right] d t$

Equation (19) has no physical meaning, it is only a useful 'trick' to represent the torque of a controlled engine/motor governed by the speed error.

Equation (19) is able to represent the general engine torque transient, without any particular protection (torque positive limit, torque negative limit, etc.), adopted in more complex numerical models (Fig. 17), so it is suitable for simulations of manoeuvres that lay in the normal working area of the engines.

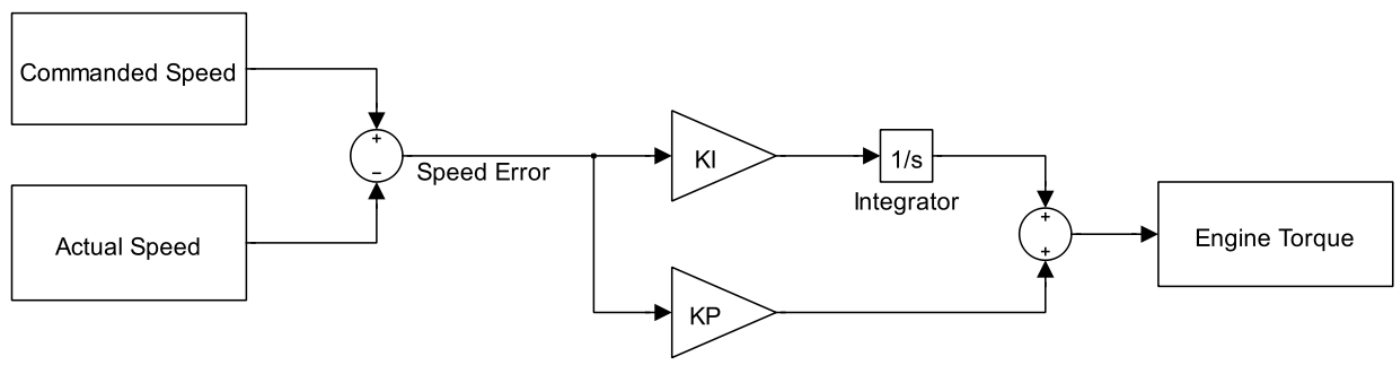

Fig.18: PI action on the speed error

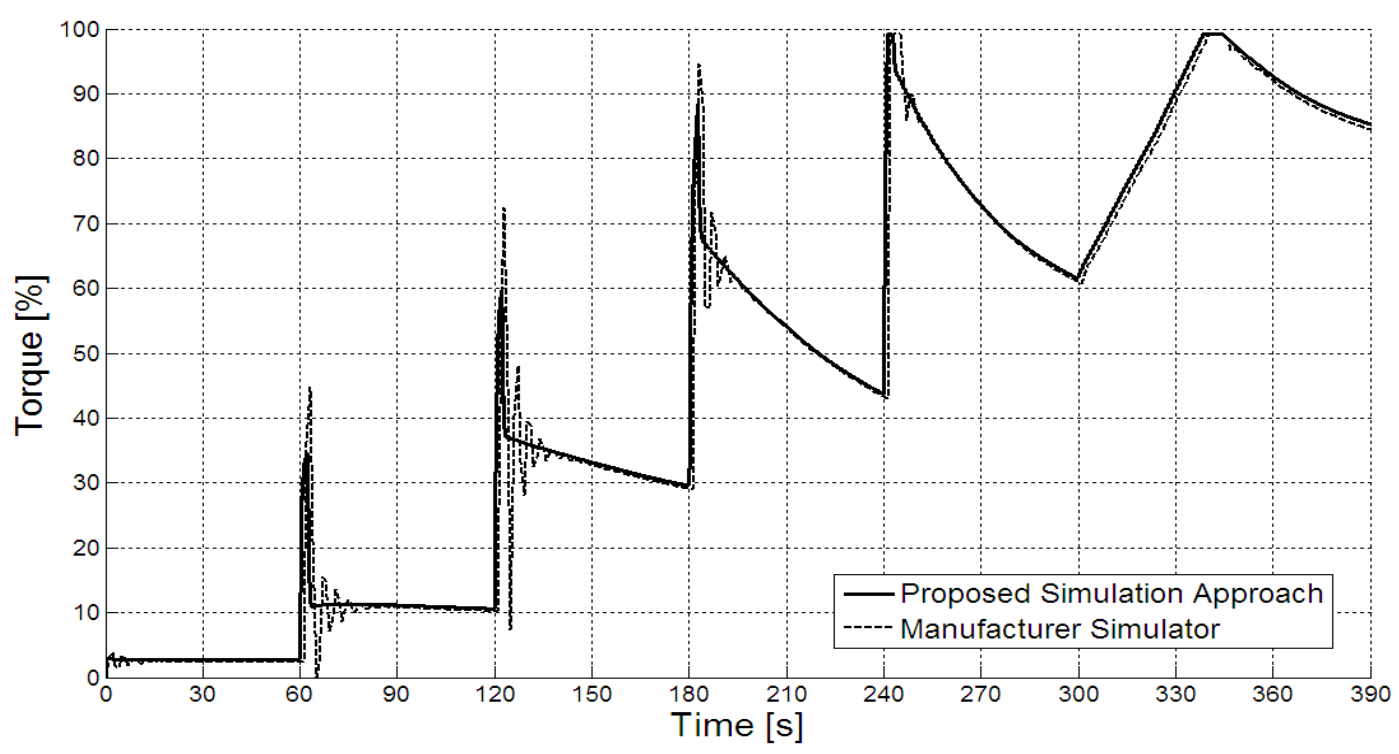

Fig.19: Comparison between the proposed method and the engine manufacturer simulator

As an example, in Fig. 19 the time history of the electric motor torque during a gradual acceleration is reported. From this figure it is possible to assess the agreement between the simulation results obtained with the proposed method and the results of the simulator kindly provided by the electric motor manufacturer. In this particular simulator, the dynamics of all the main electric components is taken into account by many thermoelectrical 
equations, which are responsible of a long computation time. The manufacturer simulator shows unstable transients probably due to the influence of the complex dynamics of the several electric components involved in the engine behaviour.

Obviously, the PI action is only a fictitious method to bypass the complex physical dynamics of the engine and then it is not able to represent the engine performance in detail. However, the PI action is a powerful tool in order to simulate the torque of every engine, since it is possible to achieve any different behaviour, for the same transient condition, by simply calibrating the values of the two constants $K_{P}$ and $K_{I}$. For instance, with regard to Fig. 19, it may be possible to achieve a more unstable transient condition, by increasing the value of $K_{I}$.

\section{Concluding remarks}

Several methods for the calculation of marine engines power (or torque) versus time, in order to investigate the general performance of the ship propulsion system, have been presented. It has been proven that the behaviour of different types of marine engines (diesel engine, gas turbine or electric motor) can be simulated by effective and simple methods, the proper choice of which, mainly depends on the engine data availability. Every proposed method can be used to assess the engine transient conditions and to design and test the layout of the propulsion control system of a ship. In the case of lack of the necessary information, one of the most suitable methods, to simulate the engine torque, may be the one based on a PI action, otherwise, the methods based on differential equations or power surfaces, derived from the engine performance maps, can represent a valid option in comparison with other too complex mathematical models.

The best model with respect to fidelity of the results certainly is the one based on physical and thermodynamic laws. However, simpler methods can be proper and more effective in order to develop simulators when very few information are available. Moreover, these methods are usually characterized by a shorter computation-time with regard to the corresponding thermodynamic models.

For these reasons, in the case of the Italian Navy FREMM project, the automation designers are actually using a propulsion simulator, developed by the authors on the basis of the engines models described in this paper, in order to design and test the layout of the propulsion controller of these frigates. The FREMM propulsion system is illustrated in Fig. 20. It is a Combined Diesel-eLectric And Gas (CODLAG) propulsion system, which consists of two shaftlines, each one driving a Controllable Pitch Propeller (CPP). Each shaft can be driven by an Electric Propulsion Motor (EPM) and/or by a Gas Turbine (GT) via a cross connected gearbox (GB). The electric motors are powered by diesel generators but they can work as Shaft Generators (SG) too.

In particular, in the developed propulsion simulator, the GT torque is actually modelled according to the simulation logic shown in Fig.13, while the simulation approach adopted for the electric motor is that one in Fig 17.

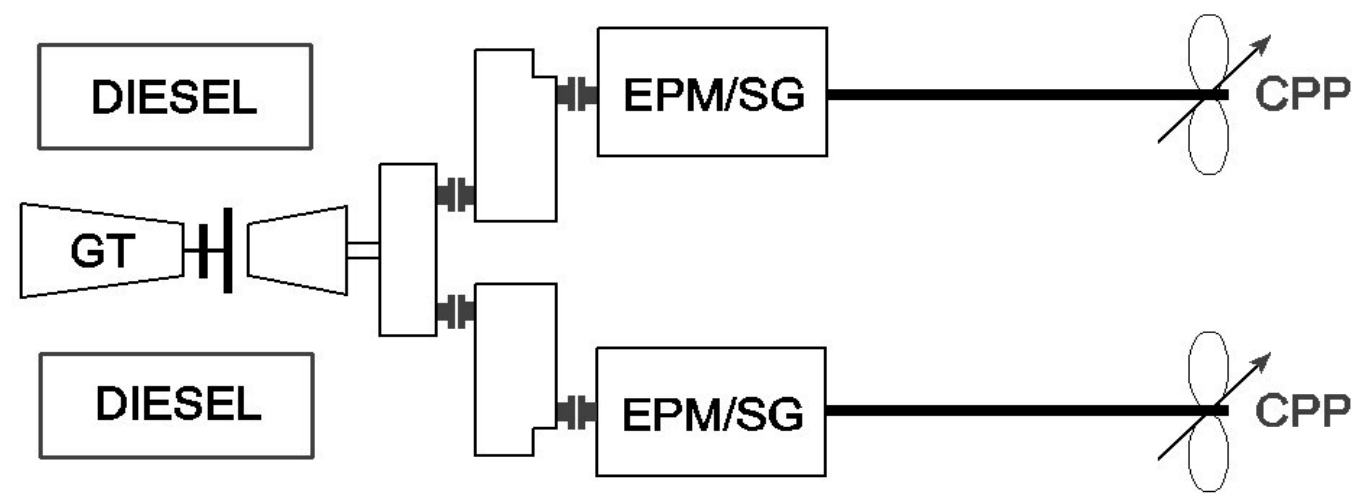

Fig. 20: Propulsion system of the FREMM Class Frigates

\section{Acknowledgments}

The authors wish to thank SEASTEMA S.p.A. and particularly Dr. G. Ottaviani for the support received during the research activity. The authors wish also to thank Fincantieri, Naval Business Unit, Genoa, and Italian Navy, General Staff, Rome. 


\section{References}

Altosole, M., Benvenuto, G., Campora, U. and Figari, M., (2004): Dynamic performance simulation of a naval propulsion system, Int. Proceedings of the Summer Computer Simulation Conference, San Jose, California.

Altosole, M. and Figari, M., (2007a): 3-D non linear ODE system for COGAG marine propulsion plants simulation, Int. Proceedings of Computational Methods in Marine Engineering II, Barcelona, Spain.

Altosole, M. and Figari, M., (2007b): Dynamic behaviour and stability of marine propulsion systems, Journal of Engineering for the Maritime Environment, Vol. 221, No. 4, pp. 187-209.

http://dx.doi.org/10.1243/14750902JEME58

Altosole, M., Benvenuto, G., Campora, U. and Figari, M., (2009): Real-Time simulation of a COGAG naval ship propulsion system, Journal of Engineering for the Maritime Environment, Vol. 223, No.1, pp. 47-61. http://dx.doi.org/10.1243/14750902JEME121

Altosole, M., Campora, U. and Figari, M., (2009): A proper use of sea trials data for marine propulsion simulations, Int. Proceedings of the 4th Int. Conference on Maritime Transport, Barcelona, Spain.

Benvenuto, G., Campora, U., Carrera, G. and Casoli, P., (1998): A two-zone diesel engine model for the simulation of marine propulsion plant transients, Int. Proceedings of the Second International Conference on Marine Industry, Varna, Bulgaria.

Benvenuto, G. and Campora, U., (2003): Dynamic performance analysis of a gas turbine/waterjet propulsion system for a fast trimaran ferry, Int. Proceedings of the 7th Int. Conference on Fast Sea Transportation, Ischia, Italy.

Benvenuto, G. and Campora, U., (2005): A gas turbine modular model for ship propulsion studies, Int. Proceedings of the 7th Symposium on High Speed Marine Vehicles, Naples, Italy.

Dimitrios, T. Hountalas, (2000): Prediction of marine diesel engine performance under fault conditions, Applied Thermal Engineering, Vol. 20, pp. 1753-1783. http://dx.doi.org/10.1016/S1359-4311(00)00006-5

Hendricks, E., (1989): Mean value modelling of large turbocharged two-stroke diesel engines, SAE 890564, Detroit, Michigan.

Kao, M. and Moskwa, J. J., (1995): Turbocharged diesel engine modeling for nonlinear engine control and state estimation, ASME Trans., Journal of Dynamic Systems, Measurement and Control, Vol. 117, pp. 20-30. http://dx.doi.org/10.1115/1.2798519

Ledger, J. D. and Walmsley, S., (1971): Computer simulation of a turbocharged diesel engine operating under transient load conditions, SAE 710177, Detroit, Michigan.

Maftei, C., Moreira, L. and Soares Guedes, C., (2009): Simulation of the dynamics of a marine diesel engine, Journal of Marine Engineering and Technology, No. A15, pp. 29-43.

Saravanamuttoo, H. I. H. and Fawke, A. J., (1971): Digital computer methods for the prediction of gas turbine response, SAE Paper, No. 710550.

Woodward, J. W. and Latorre, R. G., (1984): Modeling of diesel engine transient behavior in marine propulsion analysis, SNAME Trans., Vol. 92, pp. 33-49.

\section{Appendix: thermodynamic models used in the comparison}

The steady state comparison regarding the performance of LM2500 marine gas turbine between sea trials data and simulation is reported in Table 3. The table has been drawn analyzing several ship manoeuvres and it shows some proper simulation results, able to represent the GT performance in its entire working area. The simulation results, regarding the GT power, the gas generator speed and the inlet temperature of the power turbine, have been achieved by using, as simulation input, some proper values of the GT fuel flow consumption and GT speed, as explained in Altosole, Campora and Figari (2009); then, they are compared with the corresponding sea trials data. 
M. Altosole and M. Figari/ Journal of Naval Architecture and Marine Engineering 2(2011) 129-147

The agreement, shown in Table 3, can be considered satisfactory, even if the major discrepancies occur at the very low load factors, just to underline once again the difficulty to set up a very reliable simulator in its entire working area.

Table 3: Fidelity of the gas turbine thermodynamic model

\begin{tabular}{|c|c|c|c|c|c|c|c|c|c|c|}
\hline \multirow{2}{*}{$\begin{array}{c}\text { Fuel } \\
\text { Flow } \\
{[\%]}\end{array}$} & \multirow{2}{*}{$\begin{array}{c}\text { GT } \\
\text { Speed } \\
{[\%]}\end{array}$} & \multicolumn{2}{|c|}{ GT Power [\%] } & \multicolumn{2}{c|}{ Gas Generator Speed [\%] } & \multicolumn{3}{|c|}{ GT Temp [\%] } \\
\cline { 5 - 12 } & Trials & Sim & Error[\%] & $\begin{array}{c}\text { Sea } \\
\text { Trials }\end{array}$ & Sim & Error[\%] & $\begin{array}{c}\text { Sea } \\
\text { Trials }\end{array}$ & Sim & Error[\%] \\
\hline 9.1 & 41.8 & 1.0 & 0.9 & -17.4 & 58.0 & 58.6 & 1.0 & 51.0 & 37.0 & -27.4 \\
\hline 14.6 & 44.4 & 3.6 & 3.3 & -6.5 & 73.3 & 67.1 & -8.5 & 54.3 & 48.6 & -10.6 \\
\hline 21.9 & 45.5 & 9.0 & 9.4 & 4.8 & 80.0 & 75.6 & -5.4 & 55.7 & 55.5 & -0.4 \\
\hline 26.0 & 54.8 & 13.5 & 13.5 & 0.1 & 82.0 & 78.4 & -4.5 & 58.6 & 58.5 & -0.2 \\
\hline 32.3 & 61.1 & 19.5 & 20.5 & 5.3 & 84.1 & 81.8 & -2.7 & 62.7 & 62.2 & -0.7 \\
\hline 42.3 & 58.5 & 29.2 & 29.9 & 2.3 & 86.9 & 85.2 & -2.1 & 68.4 & 68.0 & -0.7 \\
\hline 59.2 & 85.6 & 49.4 & 49.9 & 1.0 & 89.2 & 88.9 & -0.3 & 80.7 & 79.3 & -1.7 \\
\hline 66.1 & 90.1 & 58.9 & 58.5 & -0.7 & 91.3 & 90.5 & -0.9 & 85.2 & 84.4 & -0.9 \\
\hline 84.1 & 100.4 & 80.3 & 80.4 & 0.2 & 94.8 & 94.8 & 0.1 & 94.5 & 95.0 & 0.6 \\
\hline
\end{tabular}

